\title{
PELATIHAN PENGGUNAAN APLIKASI MENDELEY BAGI MAHASISWA DALAM PENULISAN KARYA ILMIAH
}

\author{
Dina Syarifah Nasution ${ }^{1}$, Cut Dara Ilfa Rahila ${ }^{2}$, Muhammad Hasyimsyah Batubara ${ }^{3}$ \\ ${ }^{1}$ STAIN Mandailing Natal Sumut, ${ }^{2,3}$ IAIN Takengon, Aceh Tengah, Aceh, Indonesia \\ email: dinasyarifahnasution1982@gmail.com ${ }^{1}$,dara.rahila@gmail.com², \\ muhammad.hasyimsyahbatubara@gmail.com ${ }^{3}$
}

\begin{abstract}
The latest rules for publication in accredited journals and international journals require writing citations in articles by utilizing citation $\&$ reference managers such as Mendeley. Students in our observations still write citations and bibliography in scientific works manually, and then do not have the insight to use Mendeley. The impact of implementing community service is to lift the weight of student scientific work with a citation ability approach. The approach applied is lecture, practice, and question and answer. The partners in this program are 13 students of the Fifth Semester of English Language Study Program at IAIN Takengon. The impact of the activity showed that there was a new understanding and an increase in the ability of participants to operate and make quotations with Mendeley, so that students felt easy to write and developed the degree of scientific work.
\end{abstract}

Keywords: Training, Mendeley, Scientific Work

\begin{abstract}
Abstrak: Aturan terbaru dalam publikasi di jurnal terakreditasi dan jurnal internasional mengharuskan penulisan citasi dalam artikel dengan memamfaatkan citation \& reference manager seperti Mendeley. Mahasiswa dalam pengamatan yang kami lakukan masih menulis citasi dan daftar pustaka dalam karya ilmiah dengan cara manual, kemudian belum mempunyai wawasan memamfaatkan Mendeley. Dampak dari pelaksanaan pengabdian kepada masyarakat ini ialah untuk mengangkat bobot karya ilmiah mahasiswa dengan pendekatan kemampuan citasi. Pendekatan yang diterapkan ialah ceramah, praktek, dan tanya jawab. Adapun mitra pada program ini ialah mahasiswa Prodi Bahasa Inggris Semester V IAIN Takengon sebanyak 13 orang. Dampak kegiatan memperlihatkan adanya pemahaman baru dan peningkatan kemampuan peserta dalam mengoperasikan dan membuat kutipan dengan Mendeley, sehingga mahasiswa merasa mudah menulis dan terbangun drajat karya ilmiah.
\end{abstract}

Kata Kunci: Pelatihan, Mendeley, Karya Ilmiah

\section{Pendahuluan}

Pada era sekarang tidak dipungkiri kemampuan mahasiswa dalam menulis artikel ilmiah sangat penting didorong lebih produktif. Kemampuan meramu tulisan dan publikasi artikel merupakan tuntutan yang nyata dalam membangun ekosistem pendidikan yang berkualitas secara khusus dan membangun peradapan yang lebih baik pada umumnya. Menulis ilmiah merupakan salah satu basis prioritas dalam aktivitas belajar dan mengajar yang harus di pupuk pada tingkatan perguruan tinggi sehingga kecakapan menulis sungguh esensial untuk ditingkatkan (Karim \& Mursitama, 2015:5 dalam Yanti, et al., 2018). Dikutip dari KBBI menulis merupakan i. membuat huruf (angka dan sebagainya) dengan pena (pensil, kapur, dan sebagainya), ii. melahirkan pikiran atau perasaan (seperti mengarang, membuat surat) dengan tulisan, iii. menggambar; melukis, iv. membatik (kain) (KBBI, 2016). Sedangkan pendapat Swales \& Jhon dalam Lele dkk., (2010:5) dalam Yanti, et al., (2018) mengutarakan bahwa menulis akademik merupakan ragam aktivitas meramu kata yang memakai kaidah-kaidah khusus yang diterima dalam masyarakat akademik. Pada kenyataannya bagi sebagian 
mahasiswa kegiatan menulis merupakan beban yang sangat berat, padahal menulis sebenarnya kegiatan yang tumbuh dari pembiasaan.

Realita dan kenyataan sekarang mahasiswa Indonesia masih rendah dalam kegiatan menulis, hal ini dapat dilihat dari tingkat publikasi yang ada. Menurut data Nature Publishing Index Asia Pasific sebagai badan penerbit jurnal ilmiah seluruh Asia Pasifik mengeluarkan daftar publikasi karya ilmiah dalam periode 2014 s.d. 2015, menempatkan Indonesia bertengger diposisi ke-12 dari 20 negara se Asia Pasifik (Persadha, 2016 dalam Heriyudanta, 2021). Untuk meningkatkan minat menulis dan publikasi mahasiswa perlu perhatian dan dukungan dari dosen dan universitas. Cara dan strategi menulis perlu diberikan kepada mahasiwa secara berkelanjutan, sehingga memberikan wawasan dan pada akhirnya membangun minat dan kebiasaan mereka untuk menulis secara rutin.

Kemampuan menulis ini perlu didukung juga dengan aplikasi dan software pendukung yang sekarang banyak tersedia, sehingga membantu dalam penyusunan artikel. Seperti dalam pengutipan (citation) yang rasanya tidak dimungkinkan lagi dengan cara manual. Citasi merupakan bagian prinsipil dalam kegiatan penulisan karya ilmiah, melalui "citation \& reference manager" pengarang mampu menggarap dokumentasi referensi yang ada, merancang rumpun bersandarkan pada topik dan kelompok tertentu, sekalian me-retrieve metadata yang tersimpul di dalam dompet arsip (Perpustakaan Universitas Gadjah Mada, 2017). Pada masa sekarang aplikasi yang ada dalam pengutipan sudah sangat banyak, seperti aplikasi Mendeley. Mendeley merupakan perangkat lunak yang kemunculannya terinspirasi dari iktiar untuk memadukan "citation $\&$ reference manager" ke jejaring sosial, melalui penggabungan sejenis ini, peneliti dari seluruh penjuru bumi dapat bermitra dan melaksanakan pertukaran informasi dan dokumen penelitian (Perpustakaan Universitas Gadjah Mada, 2017). Mendeley sekarang ini tersaji dalam dua versi yaitu Desktop dan Institutional Edition (Perpustakaan Universitas Gadjah Mada, 2017). Lewat penjelasan diatas, perlu dilakukan pelatihan kepada mahasiswa untuk mengenal dan mampu menggunakan Mendeley Desktop Edition dengan baik. Sehingga dalam penulisan artikel ilmiah, mahasiswa dapat lebih baik lagi kedepannya.

\section{Metode}

Implementasi gerakan pelatihan ini dilakukan kepada mahasiswa pada Prodi Tadris Bahasa Inggris semester V IAIN Takengon Aceh sejumlah 13 orang. Pendekatan yang dilakukan dengan kuliah, praktek, dan diskusi. Rangkaian aksi dengan mengikuti proses persiapan, pelaksanaan, dan evaluasi. Jenjang persiapan yaitu dengan meminta peserta membawa laptop, menyiapkan email aktif, dan menyediakan artikel ilmiah masingmasing. Tahapan penyelenggaraan pelatihan pemakaian software Mendeley yaitu pemaparan materi, dan latihan secara langsung.

\section{Hasil dan Pembahasan}

Aktualisasi program pengabdian kepada masyarakat ini menerima animo dan penerimaan yang baik dari mahasiswa, karena tema kegiatan pelatihan ini adalah 
kebutuhan dalam kegiatan penyususnan skripsi. Substansi yang dipaparkan dalam kegiatan ini meliputi bagaimana pemasangan software Mendeley, mengoperasikan Mendeley desktop setup, selanjutnya install ms word plugin dan web importer, menggunakan Mendeley untuk membina citasi dan referensi, selanjutnya mununggangi tools yang lain yang terdapat pada Mendeley. Ditahapan pemasangan software Mendeley, diberikan pra aktualisasi kegiatan supaya jangan menghabiskan durasi yang terlalu lama.

\section{Instalasi software Mendeley}

a. Klik "download Mendeley" pada Google.

b. Klik dua kali file Mendeley-Desktop-1.8.4-win32 yang sudah diunduh.

c. Klik Next untuk menjalankan Setup Wizard.

d. Klik "I Agree" jika setuju dengan License Agreement yang ditawarkan oleh Mendeley.

e. Klik "Browse" untuk menempatkan di folder bagian mana aplikasi akan dipasang. Kita bisa mengabaikan pilihan tersebut dan langsung klik "Next" untuk meneruskan ke tahapan selanjutnya.

f. Klik Install untuk melakukan proses instalasi Mendeley Desktop.

g. Beri tanda centang pada Run Mendeley Desktop dan klik "Finish" untuk menyelesaikan proses pemasangan.

h. Pemasangan Mendeley Desktop sudah selesai (Perpustakaan Universitas Gadjah Mada, 2017).
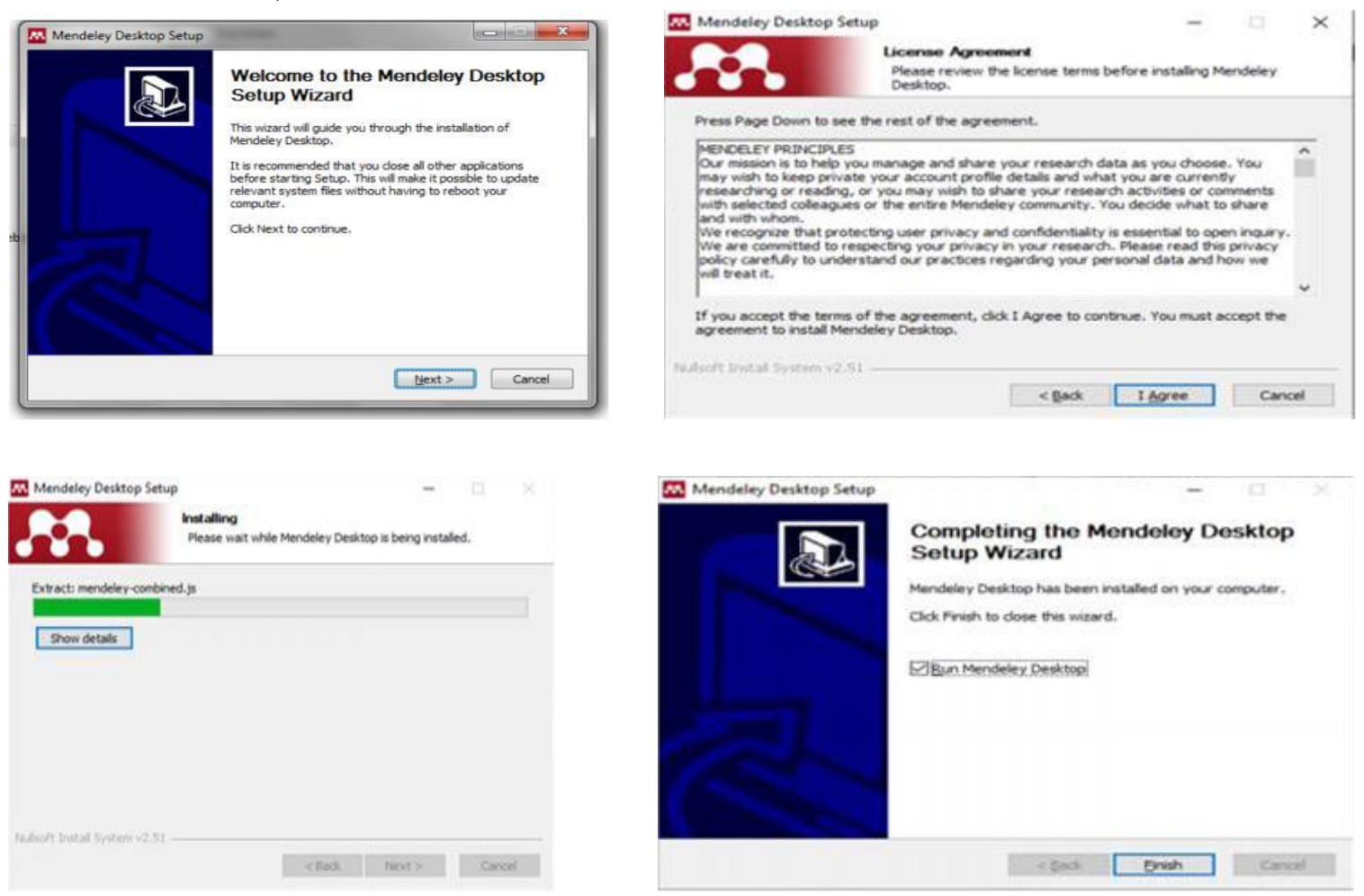

Gambar 1. Proses Instalasi Mendeley Desktop

Sesudah mahasiswa sukses memasang dan menjalankan pendaftaran akun, selanjutnya dilaksanakan pemasangan Ms Word Plugin supaya mampu dioperasikan pada Ms Word dan menyelaraskan dengan software Mendeley. 


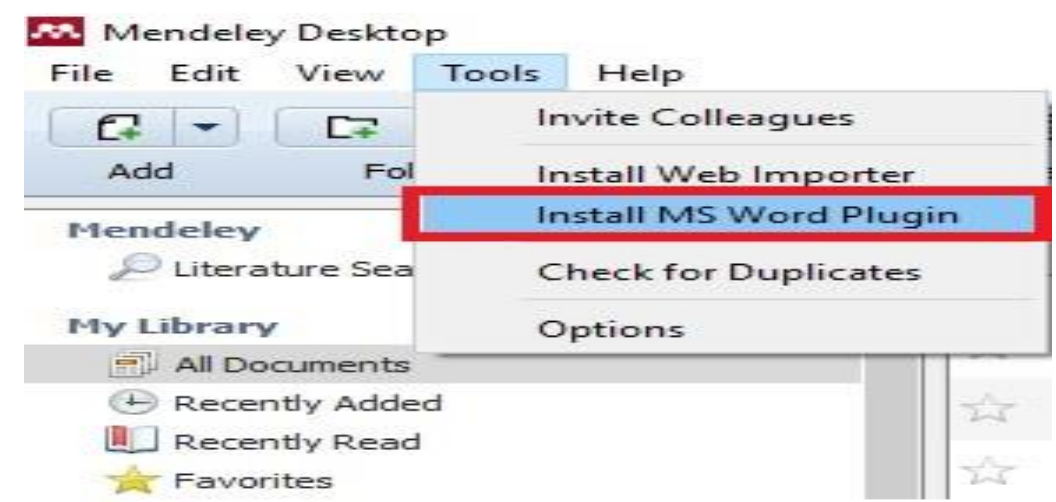

Gambar 2. Proses Instalasi Ms Word Plugin

\section{Memproduksi Citasi Dan Referensi, Manfaat Tools Lain Mendeley}

Interface Aplikasi Mendeley Desktop terdiri atas 3 bagian,

a. Kolom bagian kiri (left panel), memperlihatkan seluruh sumber daya (koleksi referensi) yang Anda miliki. My Library terbagi ke dalam folder dan kelompok. Beberapa folder secara otomatis disediakan oleh Mendeley, seperti: "recently added, favorities".

b. Kolom tengah (central panel), dipergunakan untuk menampilkan rincian daftar sumber daya referensi yang dipilih pada kolom kiri.

c. Kolom sebelah kanan (right panel), dipergunakan untuk menampilkan detail informasi dari koleksi terpilih di kolom tengah (Perpustakaan Universitas Gadjah Mada, 2017).

Sementara "Toolbar" berisi ikon membuat tugas-tugas yang bersifat umum, seperti menambah dan menghapus dokumen, mengerjakan sinkronisasi dan sebagainya. Ditempat ini juga bisa melakukan "drag and drop" maupun "right click" (Perpustakaan Universitas Gadjah Mada, 2017).

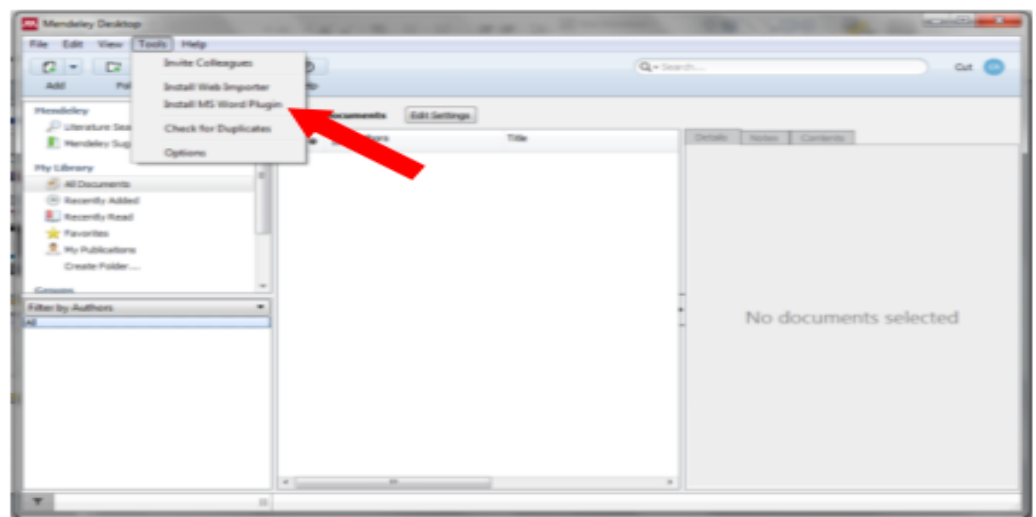

Gambar 3. Memproduksi Citasi Dan Referensi, Manfaat Tools Lain Mendeley

\section{Kegiatan Tanya Jawab}

Berikutnya peserta dibimbing untuk menyusun kutipan dengan mengoperasikan Mendeley dengan mandiri sambil melakukan aktifitas diskusi dan tanya jawab. 

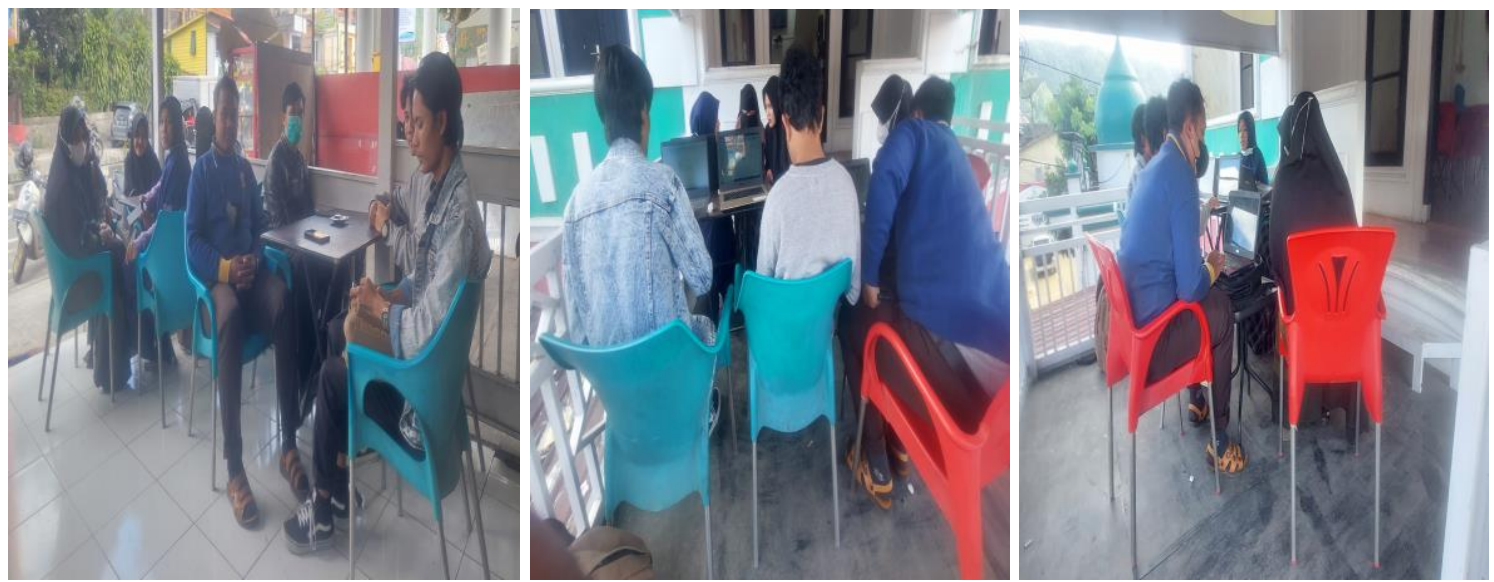

Gambar 4. Aktifitas Tanya Jawab pada pelatihan Mendeley

\section{Kesimpulan}

Dengan pelaksanaan pelatihan penggunaan software Mendeley memberikan peningkatan dan imbas pada kemampuan mahasiswa dalam citasi. Masukan pada kegiatan ini adalah perlunya kedepan pelatihan menulis karya ilmiah dengan melibatkan Mendeley dengan lebih dalam, juga diprogram kelanjutan pelatihan untuk meperbaharui kemampuan menulis dengan aplikasi dan software citasi dan referensi yang ada. Peserta yang ikut dalam kegiatan ini diharapkan dan didorong untuk dapat mengajarkan ilmu yang didapat kepada mahasiswa lain.

\section{Ucapan Terima Kasih}

Ungkapan terima kasih dikirimkan kepada segenap unsur yang terlibat dalam aktualisasi pengabdian masyarakat ini, khususnya kepada pengelola JPMA yang telah menyebarluaskan laporan kegiatan ini.

\section{Daftar Pustaka}

BPPB. (2016). KBBI Daring. Jakarta: Badan Pengembangan dan Pembinaan Bahasa, Kementerian Pendidikan, Kebudayaan, Riset, dan Teknologi Republik Indonesiah. https://kbbi.kemdikbud.go.id/entri/menulis

Heriyudanta, Muhammad. (2021). Analisis Kompetensi Menulis Karya Tulis Ilmiah Mahasiswa di Indonesia. ASCARYA: Islamic Science, Culture, and Social Studies, l(1), 61-71. https://doi.org/10.53754/iscs.v1i1.5

Karim, M. F., \& Mursitama, T. N. (2015). Menulis Akademik. Depok: Linea Pustaka.

Lele, G., \& Dkk. (2010). Panduan Penulisan Akademik. Yogyakarta: Fisipol UGM.

Retrieved from infeksius.com/wp-content/uploads/2017/01/Menulis-Akademik.pdf

Perpustakaan Universitas Gadjah Mada. (2017). Pengantar \& Instalasi Mendeley. Yogyakarta: Perpustakaan Universitas Gadjah Mada.

Retrieved from http://lib.ugm.ac.id/ind/?page_id=336

Persadha, D. (2016). Studi Kompetensi Kemampuan Menulis Di Kalangan Mahasiswa. Muaddib: Studi Kependidikan dan Keislaman, 6(1), 1 - 20.

doi:http://dx.doi.org/10.24269/muaddib.v6i1.159 
Yanti, N., Suhartono, S., \& Hiasa, F. (2018). Keterampilan Menulis Akademik Mahasiswa S-1 Program Studi Pendidikan Bahasa dan Sastra Indonesia FKIP Universitas Bengkulu. Silampari Bisa: Jurnal Penelitian Pendidikan Bahasa Indonesia, Daerah, Dan Asing, 1(1), 1-16.

https://doi.org/https://doi.org/10.31540/silamparibisa.v1i1.4

Internet:

https://www.mendeley.com/guides/desktop/

https://www.mendeley.com/download-reference-manager/linux

https://www.mendeley.com/reference-management/web-importer

https://www.mendeley.com/reference-management/reference-manager

https://www.mendeley.com/reference-management/mendeley-desktop

https://www.mendeley.com/guides

https://www.mendeley.com/?interaction_required=true

https://www.elsevier.com/solutions/mendeley 